\title{
Promoting Infant Oral Health Care
}

\section{Neeta Ghimire*}

Department of Pedodontics and Preventive Dentistry, Chitwan Medical College Teaching Hospital, Chitwan, Nepal

Infant oral health is the foundations upon which preventive education and dental care must be built to enhance the opportunity for a lifetime free from preventable oral disease [1].

Poor oral health is a major public health problem especially in the underdeveloped countries. Caries is the most common chronic oral condition among children. Early childhood caries and the more severe form of ECC can be particularly virulent forms of caries, beginning soon after tooth eruption, developing on smooth surfaces, progressing rapidly and having a lasting detrimental impact on the dentition [2-7]. The Centres for Disease Control and Prevention reports that caries is the most prevalent infectious disease. More than $40 \%$ of children have caries by the time they reach kindergarten [8].

Parents play an important role in achieving the best oral health outcomes for their young children. Very young children are dependent on their mothers to attend to their oral hygiene and feed them [9]. It has been reported that the children of mothers who have received oral health education during pregnancy have better oral health status. The association of poor maternal oral health to pre-term/low birth weight baby has been documented. Enamel defects are more common in children born prematurely, thus making these teeth more susceptible to early childhood caries [10].

Child's oral health is a particularly important part. Earlier a child receives preventive oral health services, the lesser he or she is at risk of developing dental disease. The American Academy of Pediatric Dentistry recommends that infants should have an initial oral evaluation within six months of the eruption of the first primary tooth but no later than one year of age [11].

Physicians are the first health professionals to come in contact with the expectant parents and parents of infants [12]. Parents do visit the physicians for examination and immunizations for their children. So, these visits are an ideal time to provide screening, anticipatory guidance and appropriate need based referrals.
Oral health is an integral to general health, so one should emphasize on the importance of oral health, prevention of most common dental disease like dental caries. So, Establishing a dental home, providing parental counselling, anticipatory guidance may help. Organising community based activities, oral health camps, may be used to emphasize on the importance of oral health.

\section{References}

1. American Academy of Pediatric Dentistry (2004) Clinical guidelines on infant oral health care. Pediatr Dent 26: 67-70.

2. Nowak AJ, Warren JJ (2000) Infant oral health and oral habits. Pediatr Clin North Am 47: 1043-1066

3. Gray MM, Marchment MD, Anderson RJ (1991) The relationship between caries experience in deciduous molars at 5 years and in first permanent molars of the same child at 7 years. Community Dent Health 8: 3-7.

4. Grindefjord M, Dahllof G, Modeer T (1995) Caries development in children from 2.5 to 3.5 years of age: A longitudional study. Caries Res 29: 449-454.

5. O' Sullivan DM, Tinanoff N (1996) The association of early dental caries patterns with caries incidence in presechool children. J Public Health Dent 56: 81-83.

6. Johnsen DC, G erstenmaier JH, Disantis TA, Berkowitz RJ (1997) Susceptibility of nursing caries children to future approximal molar decay. Pediatr Dent 19: $37-41$

7. Heller KE, Eklund SA, Pittman J, Ismail AA (2000) Associations between denta treatment in the primary and permanent dentitions using insurance claims data. Pediatr Dent 22: 469-474.

8. Guidelines on Infant Oral Health Care (2011) Reference Manual 6: 124-128.

9. Shivaprakash Pk, Elango I, Baweja Dk, Noorani HH (2009) The state of infant oral healthcare knowledge and awareness: Disparity among parents and healthcare professionals. J Indian Soc Pedod Prevent Dent 27: 39-43.

10. Gupta A, Marya CM, Dahiya V, Mittal R, Bhatia HP (2010) Promoting infant oral health $(\mathrm{IOH})$ care in India. J Nepal Dent Assoc 2: 207-209.

11. Sanchez OM, Childers NK (2000) Anticipatory guidance in infant oral health: Ratonale and recommendations. Am Fam Physician 61: 115-124.

12. Sanchez OM, Childers NK, Fox L, Bradley E (1997) Physicians views on pediatric preventive dental care. Pediatr Dent 19: 377-383.
*Corresponding author: Neeta Ghimire, Assistant Professor, Department of Pedodontics and Preventive Dentistry, Chitwan Medical College Teaching Hospital, Chitwan, Nepal, Tel: 9842558900; E-mail: neetag@hotmail.com

Received December 13, 2013; Accepted December 23, 2013; Published December 24, 2013

Citation: Ghimire N (2013) Promoting Infant Oral Health Care. J Mass Communicat Journalism 4: e151. doi:10.4172/2165-7912.1000e151

Copyright: (c) 2013 Ghimire N. This is an open-access article distributed under the terms of the Creative Commons Attribution License, which permits unrestricted use, distribution, and reproduction in any medium, provided the original author and source are credited. 